Article

\title{
Determining the Relationship between Residential Electricity Consumption and Factors: Case of Seoul
}

\author{
Min-Jeong Kim
}

Department of Consumer Economics, Sookmyung Women's University, 100 Cheongpa-ro 47-gil, Yongsan-gu, Seoul 04310, Korea; min-jeong.kim@sookmyung.ac.kr; Tel.: +82-2-2077-7818

Received: 5 September 2020; Accepted: 14 October 2020; Published: 16 October 2020

\begin{abstract}
This paper aims to determine the relationship between residential electricity consumption and other factors by analyzing the correlation and multiple regression between residential electricity consumption and three variables which are known as the factors affecting residential electricity consumption. We used the electricity consumption, income, number of household members, and age of 25 autonomous districts in Seoul as data for analysis, assuming that the socio-demographic characteristics vary from district to district in Seoul. The results showed that the electricity consumption and the three variables each had a significant correlation. However, multiple regression analysis results showed that the income and the number of household members have an effect on electricity consumption, but the average age is not a factor influencing electricity consumption. The results of this study would be useful for understanding the characteristics of urban residential electricity consumption in situations where the needs for an increase in residential electricity rates are continuously coming out.
\end{abstract}

Keywords: residential electricity consumption; income; number of household members; age; correlation; multiple regression analysis

\section{Introduction}

Currently, six electricity tariff systems are used for electricity pricing in Korea. These systems are prepared for electricity rates according to the type of electricity consumption for various facility purposes, including residential, general, educational, industrial, agricultural, and street lighting usage [1]. Different usages have different prices because supply costs vary according to the conditions of electricity usage such as voltage, load rate, usage time, and customer cost [2]. For residential use, a progressive rate system is applied according to electricity consumption volume, unlike rate systems for other purposes. This progressive rate structure of residential usage was introduced in 1974 for the purpose of saving electricity energy consumption and protecting the low-income class due to the surge in energy prices while experiencing the first oil shock in 1973. Since then, the progressive rate structure has been applied until now by changing the progressive stage and the progressive rate according to international oil prices and electricity supply and demand conditions [1]. This progressive rate system is done not only in Korea, but also in other countries. By adopting a progressive system for public utility charges that are directly connected to the real life of the people, such as electricity bills and water bills, it aims to curb demand and assist low-income families [3].

According to Enerdata [4], a European energy consulting firm, Korea's electricity consumption in 2018 totaled 526 TWh, which is the sixth largest in the world. It is pointed out that the use of electricity is relatively higher than the size of the economy and population. The electricity used for residential use totaled 70,687 GWh, a $6.3 \%$ increase from the previous year, and recorded the highest level in 25 years since the aggregation of power statistics in 1993 [5]. This is attributed to the increased operation of air conditioners due to the extreme heat wave in the summer of 2018 [6]. Another reason could be 
interpreted to be that Korea's residential electricity bill is the third lowest among the Organization for Economic Cooperation and Development (OECD) 33 countries [7]. Nevertheless, the temporary progressive system easing measures during the summer period were implemented in response to the extreme heat wave in the summer of 2018, and it is still easing the burden of electricity bills by raising the upper limit of stages during the summer [8].

Meanwhile, according to International Energy Agency (IEA) annual report [9], global energy consumption in 2018 increased at nearly twice the average rate of growth since 2010. Driven by higher energy demand in 2018, global energy-related carbon dioxide $\left(\mathrm{CO}_{2}\right)$ emissions rose $1.7 \%$ to a historic high of $33.1 \mathrm{Gt} \mathrm{CO}_{2}$. Korea played a part in increasing carbon emissions, showing an increase in carbon emissions (2.8\%), which is seven times higher than the average of OECD member countries [10]. In order to reduce carbon emissions, it is necessary to increase the electricity rates produced by coal power generation, increase the proportion of liquefied natural gas (LNG) power generation instead of coal power generation, and actively expand renewable energy. Although the LNG fuel cost has recently dropped significantly, the unit price of LNG power generation is still higher than that of coal power generation [11]. In addition, since the generation cost of renewable energy is still expensive [12], it can be said that an increase in electricity rates is inevitable until the "grid parity" (when the cost of the alternative energy becomes equal to or less than electricity from conventional energy forms like fossil fuels) is reached.

As such, in a situation where an increase in electricity rates is inevitable due to the rising fuel costs for electricity generation, Korea, which is on the cheaper side of electricity rates in the world, continues to offer discounts on summer electricity rates since the heat wave in 2018. Therefore, in order to check whether the cost per household due to the increase in electricity rates is feasible, we will examine the factors that affect electricity consumption. For this purpose, this study aims to determine the relationship between residential electricity consumption and other factors by analyzing the correlation and multiple regression between the residential electricity consumption and three variables (income, number of household members, and age), which are known as the factors affecting the residential electricity consumption.

In general, studies that derive various factors affecting the residential electricity consumption have been mainly conducted for all households by using multiple regression or quantile regression $[13,14]$. In fact, these studies were analyzed with a sample and Kim [14] used the household energy consumption sample survey of 2520 households nationwide conducted by the Korea Energy Economics Institute. However, in this study for Seoul metropolitan city, which is the capital and largest city in Korea and has the highest average electricity consumption per household in Korea, we use the actual electricity consumption values of the Korea Electric Power Corporation (KEPCO) and the actual values of complete enumeration surveys on the factors affecting electricity consumption. We explain the relationship between residential electricity consumption and the factors affecting electricity consumption in 25 autonomous districts in Seoul using correlation analysis and multiple regression analysis. To that end, first of all, we look at the electricity consumption per household in 25 autonomous districts in Seoul. Additionally, we try to find out the correlation between the residential electricity consumption and the three variables that are expected to affect residential electricity consumption through the data of each autonomous district in Seoul. Next, we analyze the determinants of residential electricity consumption using multiple regression analysis. Finally, based on the analyzed results, we propose a need to reform electricity rates.

\section{Background}

The residential electricity bill in Korea is a two-part charge consisting of a basic charge and a power charge [1]. The basic charge is a charge for recovering fixed costs and facility investment costs for maintaining facility availability, and is determined in consideration of system simultaneous load rates, type load rates, and usage. The power charge is a charge for recovering the short-term fluctuation rate that varies with the amount of electricity consumption [3]. In addition, charges, including a 
value-added tax (VAT) and a power industry infrastructure fund, are added. The power industry infrastructure fund is a fund created in the process of restructuring the power industry, and is intended to be used in various ways in the power field, but as the name or purpose of the fund reveals, it is being invested in "building the power industry base" [15]. Therefore, in order to calculate the electricity bill, the basic charge and the power charge are summed, and then the VAT $(10 \%)$ and the power industry infrastructure fund $(3.7 \%)$ are added.

The unit price of the basic charge and the power charge differs depending on the electricity supply method (low voltage, high voltage). The low voltage is used in detached houses, terraced houses, and low-rise apartments, which are the houses without electric power transformers, while the high voltage is used for houses with electric power transformers such as apartments with middle floors or higher. The price of high voltage is cheaper than that of low voltage, but high voltage customers are responsible for the cost of installing electric equipment, such as electric power transformers, and customer management costs, such as the collection of charges [16].

The electricity tariff system for residential area was a six-stage 11.7 times rate system from 2004 to 2016, and was eased to a three-stage 3 times rate system in December 2016 [17]. The mitigated structure was divided into three stages: indispensable interval of 0 to $200 \mathrm{kWh}$ (first-stage), average interval of 201 to $400 \mathrm{kWh}$ (second-stage), and high consuming interval of over $401 \mathrm{kWh}$ (third-stage). In the case of low voltage, rates for the power charge apply KRW 93.3 for the first-stage, KRW 187.9 for the second-stage, and KRW 280.6 for the third-stage [16]. The basic charge is also increased to KRW 910, KRW 1600, and KRW 7300 for every $200 \mathrm{kWh}$ according to the usage amount [16]. If a household used $460 \mathrm{kWh}$ in June, the basic charge is KRW 7300, the power charge is KRW 73,076 (200 kWh $\times \mathrm{KRW}$ $93.3+200 \mathrm{kWh} \times \mathrm{KRW} 187.9+60 \mathrm{kWh} \times \mathrm{KRW} 280.6)$. Following this, the VAT (10\%) and the power industry infrastructure fund (3.7\%) are added, and the final charge of KRW 91,380 is imposed.

However, the burden of electricity bills was further relieved during the summer of 2018 by collecting consumer opinions that electricity bills were still burdened by the increased operation of air conditioners due to the record-breaking heat wave in the summer of 2018. The first stage of the progressive rate system was changed from 0-200 $\mathrm{kWh}$ to $0-300 \mathrm{kWh}$, the upper limit of the second stage was from $400 \mathrm{kWh}$ to $500 \mathrm{kWh}$, and the lower limit of the third stage was $501 \mathrm{kWh}$ from the previous $401 \mathrm{kWh}$. Temporarily discounted standards were applied for two months (July-August) in the summer of 2018. Since then, the summer discount policy of 2018 has been continuously applied every summer (July-August). Compared to the summer discount policy of 2018, it is a method to reduce consumer burden by adjusting only the upper limit of the second stage to $450 \mathrm{kWh}$ [8]. Table 1 summarizes three kinds of rates (other seasons, summer discounts applied since 2019, and 2018 summer discounts) for low voltage residential electricity.

Table 1. Residential electricity rates (low voltage) $[8,16]$.

\begin{tabular}{|c|c|c|c|c|c|}
\hline Stage & $\begin{array}{c}\text { Basic Charge } \\
\text { (KRW/Household) }\end{array}$ & $\begin{array}{l}\text { Power Charge } \\
\text { (KRW/kWh) }\end{array}$ & $\begin{array}{c}\text { Other Seasons } \\
1.1 \sim 6.30,9.1 \sim 12.31\end{array}$ & $\begin{array}{l}\text { 2019 Summer } \\
\text { 7.1 8.31 }\end{array}$ & $\begin{array}{c}2018 \text { Summer } \\
7.1 \sim 8.31\end{array}$ \\
\hline 1 & 910 & 93.3 & $\sim 200 \mathrm{kWh}$ & $\sim 300 \mathrm{kWh}$ & $\sim 300 \mathrm{kWh}$ \\
\hline 2 & 1600 & 187.9 & $201 \sim 400 \mathrm{kWh}$ & $301 \sim 450 \mathrm{kWh}$ & $301 \sim 500 \mathrm{kWh}$ \\
\hline 3 & 7300 & 280.6 & $401 \mathrm{kWh} \sim$ & $451 \mathrm{kWh} \sim$ & $501 \mathrm{kWh} \sim$ \\
\hline
\end{tabular}

The summer discount policy was initiated as a measure to ensure the cooling rights of those vulnerable to the heat waves, but it is difficult to obtain a practical effect in solving the securing of the cooling rights for these people by lowering electricity bills. The energy-poor people exposed to the heat waves have many households without air conditioners, so simply cutting their electricity bills does not secure cooling rights. In fact, the summer discount policy is a measure that allows households using electricity above average to consume more electricity at lower electricity bills.

For example, if $460 \mathrm{kWh}$ is used in July, the basic charge is the same as KRW 7300, but the power charge is KRW 58,981 (300 kWh $\times$ KRW 93.3 + $150 \mathrm{kWh} \times \mathrm{KRW} 187.9+10 \mathrm{kWh} \times \mathrm{KRW} 280.6)$ with the summer discount policy, which is a reduction of KRW 14,095 from the previous price. Subsequently, 
by adding $10 \%$ VAT and $3.7 \%$ of the power industry infrastructure fund to the sum of the basic charge and the power charge, a total of KRW 75,350 will be charged, which is a KRW 16,030 discount from the KRW 91,380 before the summer discount is applied. In fact, households that use $460 \mathrm{kWh}$ per month are households that use a lot of electricity, and it is questionable whether the KRW 16,030 reduction for one month in those households will help the household economy.

As of 2018, the average monthly household income of two or more households in Seoul was estimated at KRW 4.88 million [18] and the average monthly consumption expenditure per household was KRW 2,537,641 [19]. Of the total consumption expenditure, public transportation costs KRW 348,000 and telecommunication costs KRW 134,000 [19] but assuming that electricity usage is $300 \mathrm{kWh}$, which is the average value of the second stage, the electricity costs KRW 44,390 during the nonsummer season and KRW 32,850 during the summer. Therefore, since the electricity rates in Seoul currently account for about $1.7 \%$ of total consumption expenditure, these summer discounts are not likely to be of a great help to households, but rather can only increase the social burden. However, the average monthly household income of single-person households in Seoul was estimated at KRW 2.37 million in 2018 [18], which is much lower than that of two or more households. In particular, the average monthly income tended to decrease as individuals aged. The lowest-income individuals among the single-person households were in their 60s or above [20]. Therefore, since it is estimated that the share of electricity costs among the average monthly income for single elderly households is considered to be high, it is necessary to resolve this issue by lowering the requirements of the National Basic Living Security for single-person elderly households.

It was shown that the effect of discounted electricity rates on households was not significant. In particular, the proportion of electricity bills to household income does not seem to be significant even now. However, when the number of households and age are combined, that is, in the case of single-person elderly households, the burden of electricity bills is expected to be large, so we will examine the link between household electricity consumption and three factors (income, number, and age of household members).

Table 2 summarizes the electricity transaction results by energy sources in 2019 [12]. Korea is highly dependent on nuclear energy and coal to stably support the increasing demand for electricity due to urbanization and industrial development. The new government (2017.5 ) has announced plans to gradually reduce nuclear power and coal power, expand eco-friendly power centered on renewable energy, and increase the amount of LNG power generation by reducing the cost gap between coal and LNG power generation by reflecting social and environmental costs [21].

Table 2. Electricity transaction results by energy sources in 2019 [12].

\begin{tabular}{ccccccc}
\hline & $\begin{array}{c}\text { Nuclear } \\
\text { Energy }\end{array}$ & Coal & LNG & $\begin{array}{c}\text { Renewable } \\
\text { Energy }\end{array}$ & Others & \\
\hline Transaction volume (GWh) & 138,607 & 217,342 & 141,933 & 33,446 & 9192 & 540,520 \\
Unit cost (KRW/kWh) & $(25.6 \%)$ & $(40.2 \%)$ & $(26.3 \%)$ & $(6.2 \%)$ & $(1.7 \%)$ & $(100 \%)$ \\
& 58.39 & 87.64 & 119.90 & 97.00 & 177.11 & $\begin{array}{c}108.008 \\
\text { (average) }\end{array}$ \\
\hline
\end{tabular}

As such, considering the domestic situation in which nuclear energy (25.6\%) and coal (40.2\%) account for $65.8 \%$ of the total electricity transaction volume in Korea in 2019, lowering electricity rates means that it is difficult to reflect the energy conversion policy of government for the time being. In this situation, it is difficult to immediately push for the direction of de-nuclear and de-coal, so radioactive materials, nuclear waste, greenhouse gases, and fine dust are generated in the process of generating electricity from nuclear and coal power plants. Therefore, if electricity bills are cut as a countermeasure against heat waves caused by climate change, the burden of increasing electricity consumption will have an adverse effect on accelerating not only Korean society but also climate change. In addition, as shown in Table 2, the average unit cost of electricity transaction was KRW 108.01/kWh, whereas the average unit price for residential electricity rates was KRW 104.95/kWh as of 31 December 2019 [12], 
which means that consumer rates are not properly reflecting the change in cost of wholesale market. Therefore, it is necessary to revise the residential electricity tariff system to reflect the change in the cost of the wholesale market, rather than utilize the summer discount for the power charge.

\section{Data Source and Analysis}

\subsection{Electricity Consumption by City and Province of Korea in August 2018}

In the summer of 2018, there was a record heat wave in Korea, with 31.5 days of heat wave observation, the highest number since 1973. Seoul recorded $39.6{ }^{\circ} \mathrm{C}$, the highest temperature since 1907 when meteorological observations began, and Hongcheon recorded the highest temperature in Korea at $41.0^{\circ} \mathrm{C}$ [22]. The average electricity consumption per household by city and province of Korea in August 2018 is as shown in Table 3. Seoul metropolitan city, 6 other metropolitan cities, Sejong self-governing city, and Gyeonggi-do used more than $300 \mathrm{kWh}$. All provinces except Gyeongsangnam-do showed more than $200 \mathrm{kWh}$ and less than $300 \mathrm{kWh}$. In particular, the average electricity consumption per household in Seoul was $370.69 \mathrm{kWh}$, which is the highest among 17 cities and provinces [23].

Table 3. Average electricity consumption per household by city and province of Korea in August 2018 [23].

\begin{tabular}{ccc}
\hline Cities and Provinces of Korea & Number of Households & Average Electricity Consumption per Household (kWh) \\
\hline Seoul metropolitan city & $4,591,968$ & 370.69 \\
Busan metropolitan city & $1,646,890$ & 333.85 \\
Daegu metropolitan city & $1,202,927$ & 354.17 \\
Incheon metropolitan city & $1,345,852$ & 365.34 \\
Gwangju metropolitan city & 723,684 & 345.18 \\
Daejeon metropolitan city & 765,166 & 332.37 \\
Ulsan metropolitan city & 558,544 & 337.89 \\
Sejong self-governing city & 153,476 & 360.58 \\
Gyeonggi-do & $5,819,179$ & 364.67 \\
Gangwon-do & 849,940 & 264.08 \\
Chungcheongbuk-do & 889,502 & 292.78 \\
Chungcheongnam-do & $1,188,926$ & 286.56 \\
Jeonrabuk-do & 970,087 & 298.72 \\
Jeonranam-do & $1,007,285$ & 275.94 \\
Gyeongsangbuk-do & $1,550,610$ & 272.73 \\
Gyeongsangnam-do & $1,778,899$ & 301.58 \\
Jeju-do & 343,067 & 288.20 \\
\hline
\end{tabular}

Figure 1 shows the average monthly electricity consumption per household in 2018 in Seoul. As shown in Figure 1, August recorded the highest electricity consumption ( $370 \mathrm{kWh})$ due to the heat wave, and the electricity consumption of $200 \mathrm{kWh}$ or more was shown in the rest of the months except for August. This confirms that about $100 \mathrm{kWh}$ of electricity is additionally used in summer compared to other months. However, the summer discount will result in a one-stage lower rate for the additional $100 \mathrm{kWh}$ used. All monthly electricity consumption is an average customer segment corresponding to the second stage $(201-400 \mathrm{kWh})$ of the residential electricity tariff system. Therefore, this summer discount provides benefits to above-average customers, namely households with high electricity consumption. 


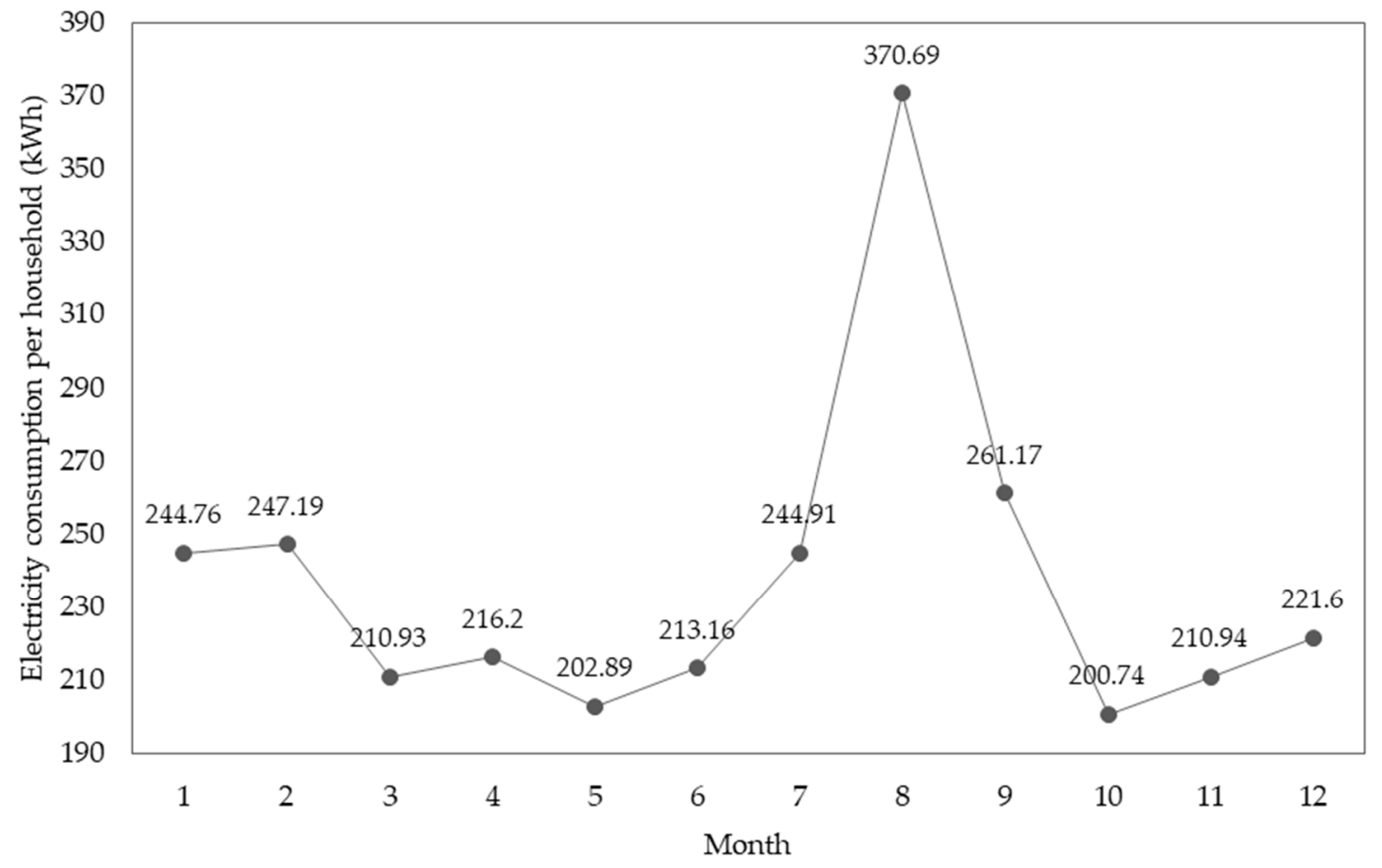

Figure 1. Average monthly electricity consumption of Seoul in 2018.

Figure 1 is based on the measurement results of all households in Seoul, and it is predicted that there will be a difference in electricity consumption by each autonomous district when Seoul is divided into 25 autonomous districts. This is because each autonomous district in Seoul had a structurally unequal infrastructure in the process of urban development in the 1970s, and this structural difference became visible in earnest through the local autonomy system in 1995, which consequently had a certain effect on the social quality of the residents of the autonomous district [24]. Therefore, we will check whether there is a difference between the autonomous districts by first examining the electricity consumption by the 25 autonomous districts in Seoul. Then, we will investigate the characteristics of residential electricity consumption by examining the correlation between each of the three characteristics (income, number of household members, age) and electricity consumption by 25 autonomous districts in Seoul.

\subsection{Electricity Consumption by 25 Autonomous Districts in Seoul in August 2018}

Seoul metropolitan city is the capital and largest city in Korea, with an area of $605.2 \mathrm{Km}^{2}$, 25 autonomous districts, and 424 administrative "dong" units. It consists of 11 autonomous districts in the south of the Han River and 14 autonomous districts in the north of the Han River [25]. At the end of April 2020, the resident population was about 9,726,787 and the household was 4,361,645, with an average population of 2.23 per household [26]. The population in Seoul has increased even more since 1960 when large-scale employment occurred, as various industries developed along with the economic growth of the Republic of Korea, which has meant that it has become overcrowded due to social increase rather than natural increase. However, the rate of net outflow of the population was the fastest among Korean cities in the 2010s due to high housing prices, and Seoul's population fell below the 10 million mark as of May 2016. Most of the population leaving Seoul is moving to Gyeonggi-do, and the deurbanization phenomenon of moving to Sejong self-governing city or Jeju-do is taking place [27].

Figure 2 summarizes the average electricity consumption per household in 25 autonomous districts in Seoul in August 2018 [23]. In total, 6 districts exceeded $400 \mathrm{kWh}$, while 18 districts used $300 \sim 400 \mathrm{kWh}$, and only 1 district, Gwanak-gu, showed less than $300 \mathrm{kWh}$. The maximum was 
$463.46 \mathrm{kWh}$ in Seocho-gu and the minimum was $294.33 \mathrm{kWh}$ in Gwanak-gu, and the difference between the two was $169.13 \mathrm{kWh}$. These results confirm that there is a difference in electricity consumption in the 25 autonomous districts in Seoul. In addition, three districts in the southeast region, Seocho-gu, Gangnam-gu, and Songpa-gu, all recorded electricity consumption exceeding $400 \mathrm{kWh}$. Seocho-gu, Gangnam-gu, and Songpa-gu are often used as the Gangnam three-gu in the media because they are proud of their high land prices and are a region where many wealthy people live [28].

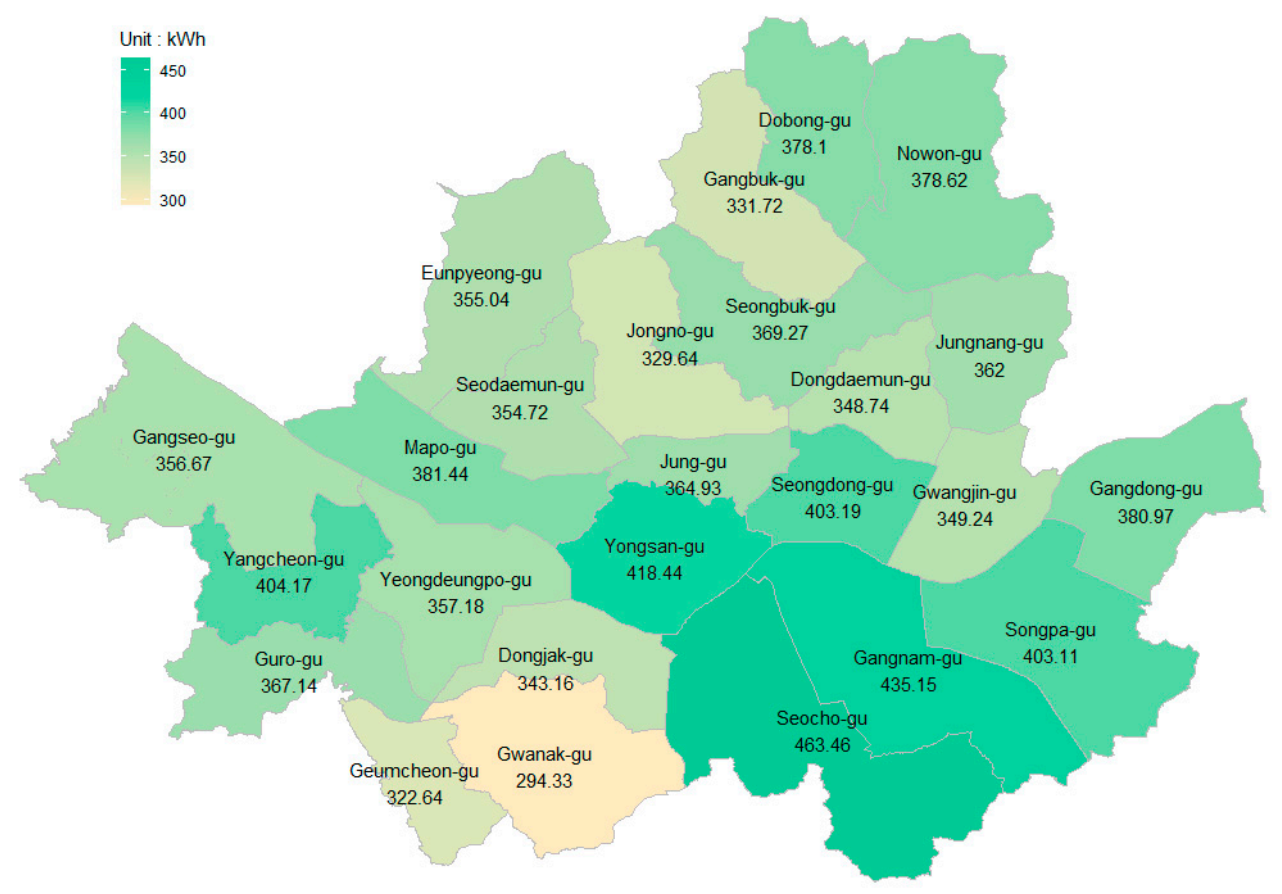

Figure 2. Electricity consumption of 25 autonomous districts in Seoul (August 2018) [23].

\subsection{Correlation Analysis of Electricity Consumption with Three Variables}

We will investigate the correlation between electricity consumption and three variables that are expected to affect electrical consumption. Correlation is a method by which the relationship between two variables can be determined [29]. In this case, the strength of the relationship between the two variables is called a correlation coefficient. The correlation can be categorized into three groups: (1) positive correlation (the correlation coefficient is greater than 0 ) - the values of the variables increase or decrease together, (2) negative correlation (the correlation coefficient is less than 0 )-as the value of one variable decreases, the value of the other increases, (3) zero correlation-the values of the variables are not correlated. In this paper, we use Pearson's correlation coefficients because both variables are continuous variables. The Pearson's correlation coefficient is the value of the covariance of the two variables divided by the product of standard deviation of the two variables [29]. Values between 0 and $0.3(0$ and -0.3$)$ indicate a weak positive (negative) linear relationship. Values between 0.3 and 0.7 $(-0.3$ and -0.7$)$ indicate a moderate positive (negative) linear relationship. Values between 0.7 and 1.0 $(-0.7$ and -1.0$)$ indicate a strong positive (negative) linear relationship.

\subsubsection{Correlation Analysis between Electricity Consumption and Income}

First, we will investigate the relationship between electricity consumption and income. The data used for this purpose are as follows. In 2015, the Korea Employment Information Service (KIPO) surveyed the Local Quality of Employment Index (LQEI), which determined how good the jobs are in each of the 17 metropolitan cities and 252 cities and counties across the country [30]. LQEI was converted into a standard score based on the analysis of the proportion of high-income (third quartile or higher), high-educated (college graduates or higher), and skilled (expert/manager) among all those 
employed by each local government. Above 1 were divided into upper regions, 0 to less than 1 were divided into middle and upper regions, 0 to -1 were middle and lower regions, and less than -1 were divided into lower regions. In this study, only the proportion of high income among the three values of LQEI was selected as a variable to examine correlation with electricity consumption. This is because there are previous studies that note that income is one of the factors affecting electricity consumption [31-34].

Figure 3 is the scatterplot of 25 autonomous districts in Seoul between the average electricity consumption per household in August 2018 and the proportion of high-income earners. The graph shows an upward-right pattern, and the calculation result of the correlation between the two variables is 0.7969 , indicating that there is a strong positive correlation $(p=0.000)$. That is, electricity consumption per household in August 2018 has a strong positive correlation with the proportion of high-income earners. The results are the same as the results of previous studies, showing that as income increases, electricity consumption increases [3,31-34]. In particular, as shown in Figure 3, the three districts with a high proportion of high-income earners are found to be the Gangnam three-gu (Seocho-gu, Gangnam-gu, and Songpa-gu) as described earlier.

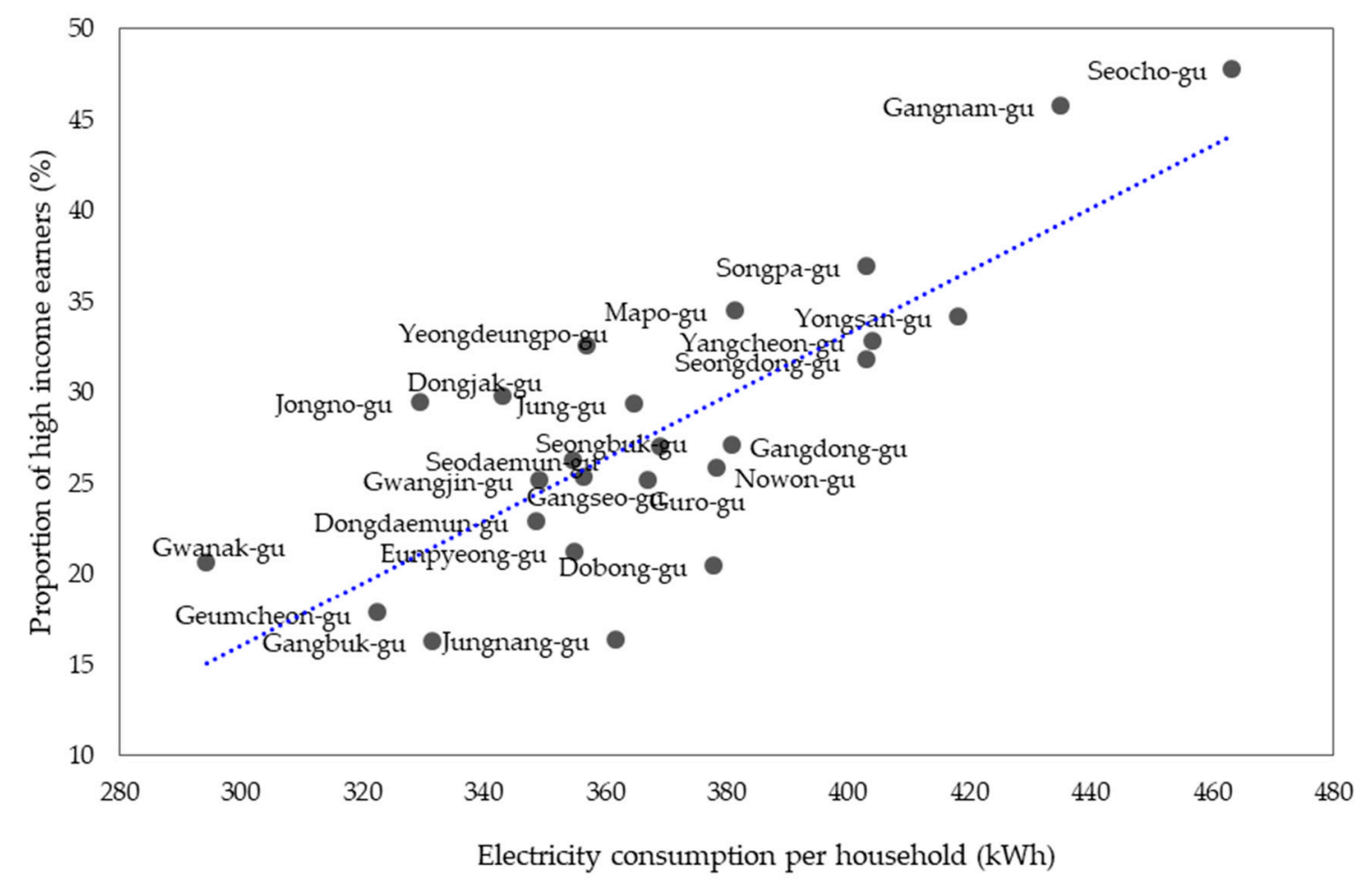

Figure 3. Scatter plot between electricity consumption and proportion of high-income earners.

\subsubsection{Correlation Analysis between Electricity Consumption and Number of Household Members}

Next, we will examine the relationship between electricity consumption and the number of household members. For this, we use the data from the Seoul Open Data Plaza provided by the Seoul Metropolitan Government [35]. The data is the number of household members by autonomous district in Seoul in 2018, and the average number of household members was calculated based on the number of households of one person to seven or more persons. Figure 4 is the scatterplot of 25 autonomous districts in Seoul between the average electricity consumption per household in August 2018 and average number of household members. 


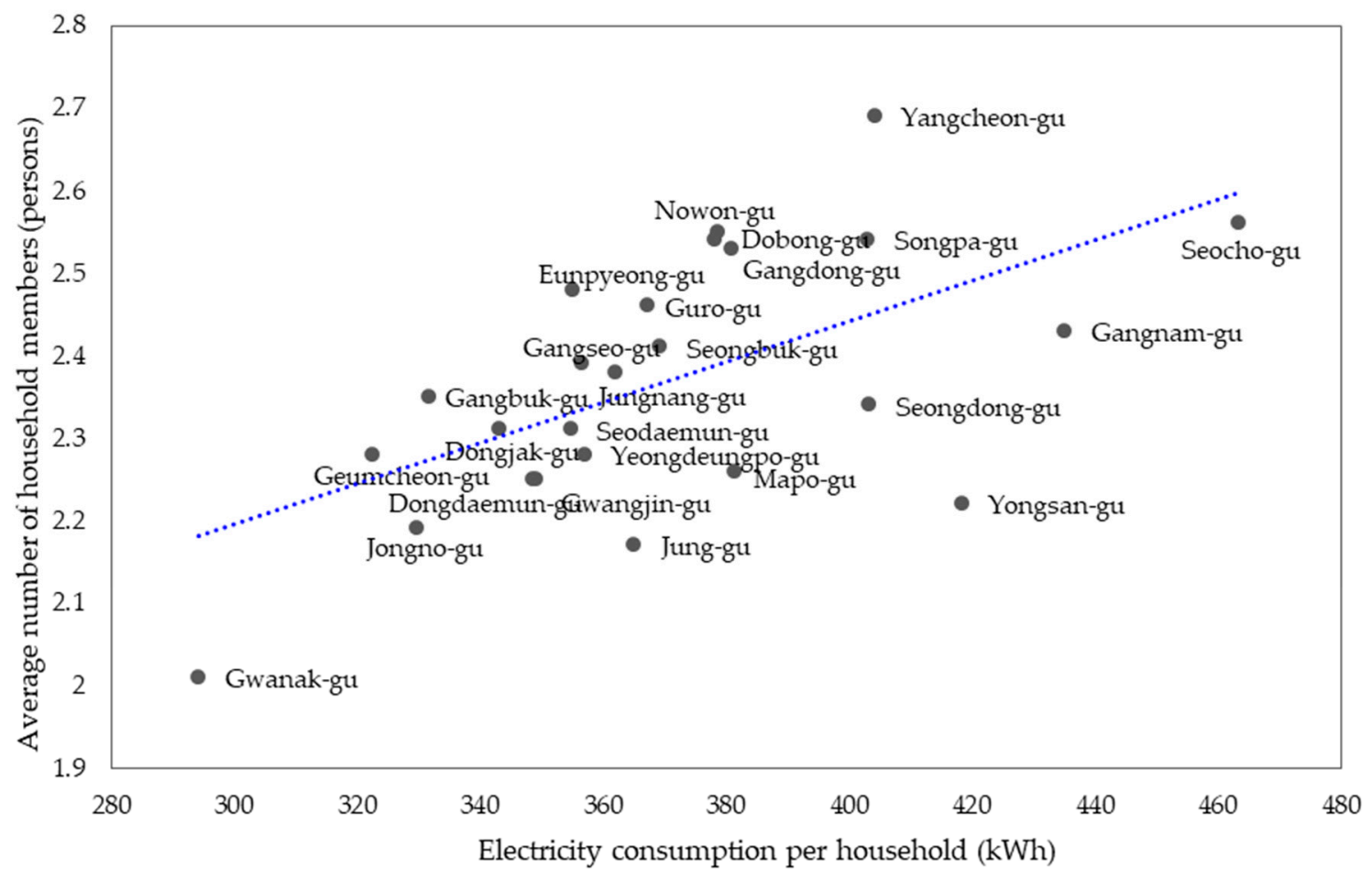

Figure 4. Scatter plot between electricity consumption and number of household members.

As shown in Figure 4, the minimum value of the average number of household members is 2.01 (Gwanak-gu), the maximum value is 2.69 (Yangcheon-gu), and the average number of household members in each autonomous district in Seoul is less than 3. In the case of Gwanak-gu, which showed the minimum value, the proportion of single-person households was $47.61 \%$ of the total households [35], and according to Byun et al. [36], Gwanak-gu showed that the proportion of single-person households was high for young people (20-39 years old) and middle-aged people (40-64 years old). Figure 4 shows that there is a positive correlation between the two variables, and the correlation coefficient is 0.588279 , confirming that there is a moderate positive correlation $(p=0.002)$. That is, electricity consumption per household in August 2018 has a moderate positive correlation with the average number of household members. The results are the same as the results of previous studies, showing that as the number of household members increases, electricity consumption increases [33,34,37].

\subsubsection{Correlation Analysis between Electricity Consumption and Age}

The following examines the relationship between electricity consumption and average age. For this purpose, the average age data for each autonomous district of Seoul in 2018 was used at the Open Data Plaza [35]. Figure 5 shows the scatterplot of 25 autonomous districts in Seoul between the average electricity consumption per household in August 2018 and average age. As shown in Figure 5, the lowest average age is Seocho-gu, which is 40.4 years old and the highest is Gangbuk-gu, which is 44.7 years old. The average age of each autonomous district is between 40 and 45 years old. There appears to be a negative correlation between the two variables, and the correlation coefficient is -0.49852 , which shows a moderate negative correlation $(p=0.011)$. This result is not consistent with a study by Yohanis who found that people aged 65 and above consumed electricity more than younger people [37]. However, Kim [20] who studied electricity consumption behavior of single-person households, claimed that the average electricity use by age group is the highest in their 30s, and the higher the age group, the lower the electricity consumption. 


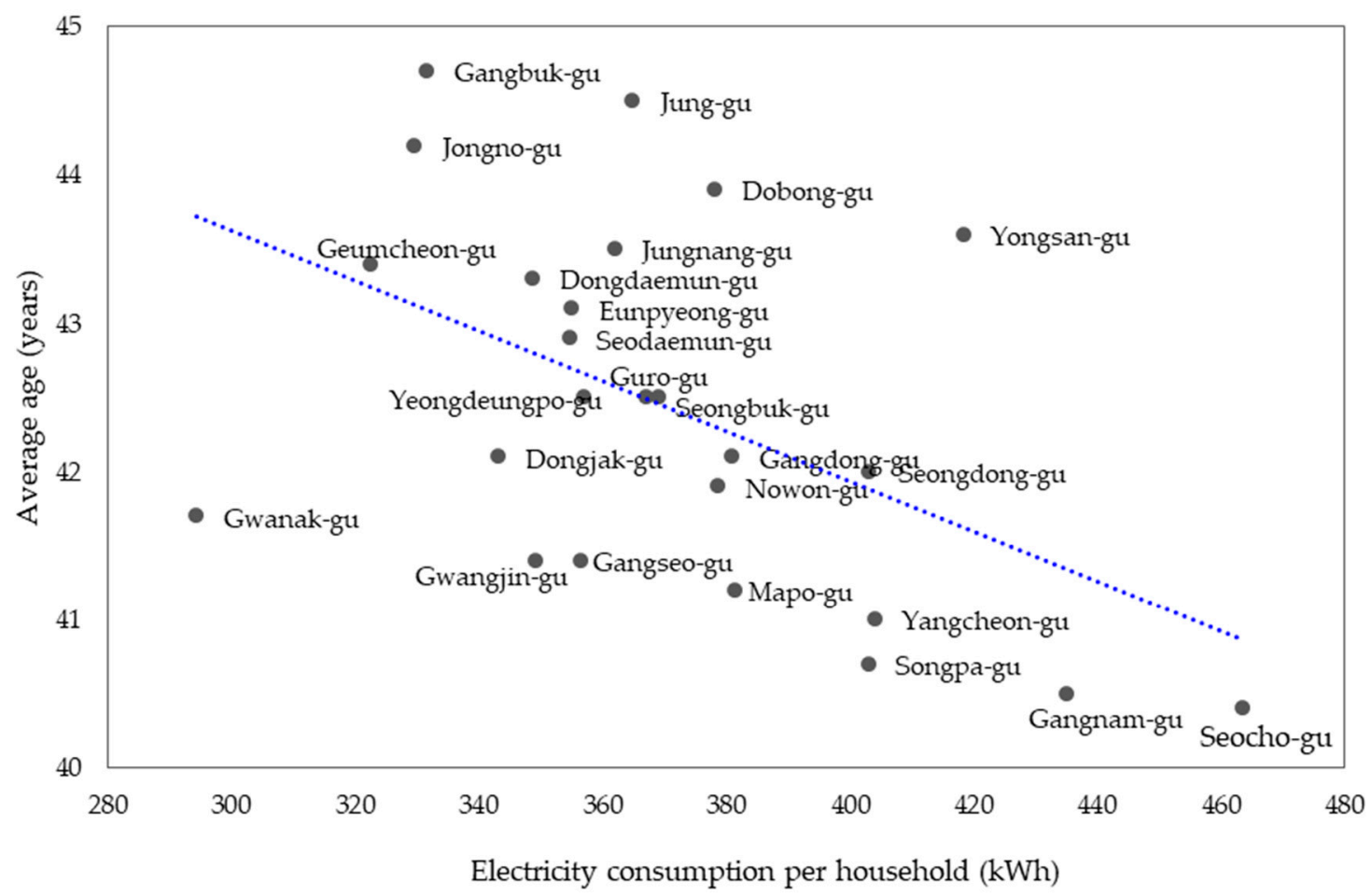

Figure 5. Scatter plot between electricity consumption and age.

So far, the correlation between electricity consumption and income, number of household members, and age has been analyzed. As a result of the analysis, it was confirmed that the higher the income, the higher the electricity consumption, the higher the number of household members, the higher the electricity consumption, and the lower the age, the higher the electricity consumption. These results can be considered to be consistent with the existing research results.

\subsection{Factors Affecting Residential Electricity Consumption}

Considering the three factors which are expected to affect residential electricity consumption of Seoul metropolitan city, we employ the following model:

$$
E C=\alpha_{0}+\alpha_{1} \cdot P H I+\alpha_{2} \cdot N H M+\alpha_{3} \cdot A A+\varepsilon,
$$

where $E C$ represents electricity consumption, $P H I$ denotes proportion of high-income earners, $N H M$ stands for average number of household members, and $A A$ is average age. The data used in this Section is the same as the data used in Section 3.3.

Table 4 illustrates the regression results for Equation (1). First, the regression model of the first quintile is significant $(\mathrm{F}=33.269, p=0.000)$ and the explanatory power of the model is $82.6 \%$. The variables that have a significant effect on residential electricity consumption are the proportion of high-income earners and average number of household members. Among these determinants, the proportion of high-income earners $(\beta=0.807)$ is more influential than the average number of household members $(\beta=0.470)$. However, average age is not an affecting factor on the residential electricity consumption. This is different from the results of correlation analysis in Section 3.3, which is estimated to be insignificant because Equation (1) is a model in which other independent variables are added. 
Table 4. Estimation results of Equation (1).

\begin{tabular}{|c|c|c|c|}
\hline & Beta Coefficient & T Statistics & $p$-Value \\
\hline$\alpha_{1}(P H I)$ & $0.807^{* * *}$ & 6.855 & 0.000 \\
\hline$\alpha_{2}(\mathrm{NHM})$ & $0.470^{* * *}$ & 4.802 & 0.000 \\
\hline$\alpha_{3}(A A)$ & 0.188 & 1.523 & 0.143 \\
\hline$R^{2}$ & 0.826 & & \\
\hline $\mathrm{F}$ & $33.269 * * *$ & & \\
\hline
\end{tabular}

\section{Discussion}

Based on these findings, we will look into the residential electricity tariff system in our country. The residential electricity tariff system has been in place for nearly 50 years with a progressive rate system to save electricity consumption and protect the low-income class. The progressive rate system is basically designed to pay low electricity rates for those below the average value, and high electricity rates for those above the average value, based on the average value of the electricity consumption of all households. Electricity should be provided to everyone, but it is not a public good. Electricity is a limited consumer product that affects the global environment and all of us. Therefore, it is natural to have to pay as much for using a lot of electricity. Since our research results show that income is derived as the factor that most affects electricity consumption, it is estimated that ordinary households can pay as much as the amount of electricity used.

Looking at our research results one by one, since electricity consumption and income have a strong positive correlation and income is the most influencing factor on residential electricity consumption, it can be said that it is appropriate to impose a high cost on households with high electricity consumption. This can also be found in studies dealing with the relationship between the electricity rate and the electricity demand. It was found that electricity demand responds to electricity rate changes inelastically [38]. In particular, high-income households showed the most inelastic response to changes in electricity rates. Next, there is a moderate positive correlation between electricity consumption and the average number of household members, so it is necessary to ease the burden on electricity bills by applying discounts to a large family with a less than median income. Lastly, our research shows that the relationship between electricity consumption and age has a moderate negative correlation but age is not a significant influencing factor on electricity consumption, so it is predicted that they will be payable for the electricity they used in the case of an age group with economic activity. However, since the proportion of electricity bill expenditure to household income for the elderly households is high [39], a separate energy welfare policy is needed for these households. Because these households have to endure the cold in winter and the heat in summer in a house with poor insulation, the benefits returned to them with the summer discount of electricity rates are not very effective.

\section{Conclusions}

This study investigated the relationship between residential electricity consumption and other factors by analyzing the correlation and multiple regression between the residential electricity consumption and three variables (income, number of household members, and age) which are known as the factors affecting the residential electricity consumption. In particular, in this study, we used actual data on electricity consumption, income, number of households, and age of 25 autonomous districts in Seoul metropolitan city, rather than sample survey data. As a factor affecting electricity consumption, housing type is also considered in previous studies $[33,34]$, but as actual data, this was not a continuous variable, so it was not applied to our analysis method.

The results showed that the electricity consumption and the three variables each had a significant correlation. Looking at specific findings, the strongest positive correlation was found between electricity consumption and income, moderate positive correlation for the number of household 
members, and moderate negative correlation for age. In addition, as a result of performing a multiple regression analysis, it was found that the share of high income and the number of household members had an effect on electricity consumption, but the average age was not a factor influencing electricity consumption. These results mean that ordinary households can pay as much as the amount of electricity used.

The reason Korea's electricity bills are low is that electricity is generated and supplied at low taxation on coal and nuclear fuel, at low external costs in terms of social and environment, and the cost of energy conversion is not reflected in the supply price. Looking at the electricity rates in Germany, which is an advanced country in energy conversion with the world's most expensive electricity bill, the electricity production charges corresponding to the power charges in Korea are about three times more expensive than in Korea (Germany: 0.31234 euro/kWh) [40]. Even so, this only accounts for a low proportion $(46 \%)$ of the total electricity bill, and taxes and levies account for almost $50 \%$ of the total electricity bill [41]. In a country where electricity production charges are three times more expensive than in Korea, the situation in which taxes and levies are higher than power production charges is to utilize them as resources for energy conversion, curb electricity consumption, and improve energy efficiency. Therefore, it is necessary to revise the residential electricity tariff system in Korea. As a result of our research, it is judged that the increase in electricity rates is not unreasonable. First of all, it is necessary to reflect the change in the cost of electricity production, and then to discuss ways to add taxes and levies in order to expand renewable energy, reduce fine dust and greenhouse gas, and prepare other energy conversion costs. As a result, taxes and levies on current electricity bills are too small compared to those of other countries, and the taxes and levies are being used regardless of energy conversion.

According to the citizens' perception survey on climate change conducted by the Korean Federation for Environmental Movement in 2016 [42], 94\% of the respondents answered that the climate change problem was serious, and $64 \%$ of the respondents said that the fossil fuel social system was the biggest cause. From the results of this survey, citizens seem to be very aware of the seriousness of the climate change problem. Perhaps our citizens in Korea are willing to pay enough for electricity produced as a clean energy source, as well as reflect the external and energy conversion costs. If citizens agree on the seriousness of climate change but are not yet ready to pay for the changed electricity bill, the government and KEPCO will have to inform citizens about the seriousness of climate change and the need for energy conversion to cope with the climate crisis and ask for consent on the realization of electricity rates.

To confirm that the increase in electricity rates is feasible in the situation that the summer discounts of electricity rates have been continued despite the inevitable increase in electricity rates due to the increase in fuel costs, we examined the factors affecting electricity consumption by correlation analysis and regression analysis. The analysis results showed that the increase in electricity rates is reasonable. However, since our research was only for Seoul, only the characteristics of metropolitan cities were reflected. In the case of small and medium-sized cities, the factors we examined in this study, such as income, number of household members, and average age, may have different characteristics from those of metropolitan cities. Therefore, the factors that affect electricity consumption by city size will be conducted in future research.

Funding: This research received no external funding.

Conflicts of Interest: The author declares no conflict of interest.

\section{References}

1. Kim, M.-J. A study of restructured residential electricity pricing toward the competitive power market. Trans. Korean Inst. Electr. Eng. 2014, 63, 889-895. [CrossRef]

2. Kim, J.S. Electric rate system and electric power load management. J. Electr. World 1992, 188, 24-30. 
3. Im, S.Y. Current status and reform direction for residential electricity charges. Mon. Public Financ. Forum 2013, 201, 8-26.

4. Enerdata. Global Energy Statistical Yearbook 2019. Available online: https://yearbook.enerdata.co.kr/ electricity/electricity-domestic-consumption-data.html (accessed on 21 June 2020).

5. Korea Electric Power Corporation. 2018 KEPCO in Brief; Korea Electric Power Corporation: Naju, Korea, 2018. Available online: https://home.kepco.co.kr/kepco/cmmn/documentViewer.po?fn=BBS_201907050252063830\& $\mathrm{rs}=/ \mathrm{kepco} /$ synap/doc (accessed on 20 June 2020).

6. Im, E.-S.; Thanh, N.-X.; Kim, Y.-H.; Ahn, J.-B. 2018 summer extreme temperatures in South Korea and their intensification under $3{ }^{\circ} \mathrm{C}$ global warming. Environ. Res. Lett. 2019, 14, 094020. [CrossRef]

7. International Energy Agency. Household Electricity Prices in Select IEA Countries, 2018. Available online: https://www.iea.org/data-and-statistics/charts/household-electricity-prices-in-select-iea-countries2018 (accessed on 28 June 2020).

8. Korea Energy Agency. Reform of the progressive rate system and the prospects and measures for electricity supply and demand in summer. Biwkly. KEA Energ. Issues 2019, 117. in press.

9. International Energy Agency. Global Energy \& $\mathrm{CO}_{2}$ Status Report 2019-The Latest Trends in Energy and Emissions in 2018, Flagship Report-March 2019. Available online: https://www.iea.org/reports/globalenergy-co2-status-report-2019 (accessed on 21 May 2020).

10. BP Statistical Review of World Energy 2019, 68th ed.; BP: London, UK, 2019.

11. Yonhapnews. 'LNG Cheaper Than Coal'... Lowest Fuel Cost Gap Ever. Available online: https://www.yna. co.kr/view/AKR20200612066400003 (accessed on 1 July 2020).

12. Korea Electric Power Corporation. 2019 KEPCO in Brief; Korea Electric Power Corporation: Naju, Korea, 2019. Available online: https://home.kepco.co.kr/kepco/cmmn/documentViewer.po?fn=BBS_202004280843308241\& rs=/kepco/synap/doc (accessed on 30 June 2020).

13. Kavousian, A.; Rajagopal, R.; Fischer, M. Determinants of residential electricity consumption: Using smart meter data to examine the effect of climate, building characteristics, appliance stock, and occupants' behavior. Energy 2013, 55, 184-194. [CrossRef]

14. Kim, M.-J. Understanding the determinants on household electricity consumption in Korea: OLS regression and quantile regression. Electr. J. 2020, 33, 106802. [CrossRef]

15. Korea Power Exchange. Power Industry Infrastructure Fund. Available online: https://www.kpx.or.kr/www/ contents.do?key=173 (accessed on 29 July 2020).

16. Korea Electric Power Corporation. Electric Rates Table. Available online: http://cyber.kepco.co.kr/ckepco/ front/jsp/CY/E/E/CYEEHP00201.jsp (accessed on 29 July 2020).

17. Kim, Y.-R.; Kim, M.-J. Characteristics and determinants of household electricity consumption for different levels of electricity use in Korea. Trans. Korean Inst. Electr Eng. 2017, 66, 1025-1031. [CrossRef]

18. Seoul Metropolitan Government. Seoul at a Glance 2019; Seoul Metropolitan Government: Seoul, Korea, 2019.

19. Statistics Korea. Monthly Average Household Expenditure Per Household (Nationwide, at Least 1 Person). Available online: http://kosis.kr/statHtml/statHtml.do?orgId=101\&tblId=DT_1L9R001\&conn_path=I2 (accessed on 3 May 2020).

20. Kim, M.-J. Electricity Consumption by Age of Single-Person Households in Korea. Fam. Consum. Sci. Res. J. 2018, 47, 42-55. [CrossRef]

21. Ministry of Trade, Industry and Energy. The 8th Basic Plan for Long-Term Electricity Supply and Demand (2017-2031); Ministry of Trade, Industry and Energy: Sejong, Korea, 2017.

22. Jo, H.-M.; Lee, Y.-H. A Study on the Improvement of response to heat waves in Seoul. Seoul Inst. Policy Rep. 2018, 257.

23. Korea Electric Power Corporation. Average Electricity Consumption Per Household. Available online: https://bigdata.kepco.co.kr/cmsmain.do?scode=S01\&pcode=000171\&redirect=Y (accessed on 13 June 2020).

24. Kim, J.-W.; Han, M.-K. Differences in "social quality" of 25 autonomous districts in Seoul. Stat. Res. Inst. 2005, 1-41.

25. Seoul Metropolitan Government. City of Seoul. Available online: http://english.seoul.go.kr/get-to-know-us/ seoul-views/meaning-of-seoul/2-location/ (accessed on 24 July 2020).

26. Ministry of the Interior and Safety. Resident Population and Household Status. Available online: http: //27.101.213.4/index.jsp (accessed on 24 July 2020). 
27. The Seoul Institute. Seoul Population Shift. Available online: http://data.si.re.kr/node/334 (accessed on 24 July 2020).

28. Choi, J.I.; Lee, O.D. Analysis of Trends and Future Prospects of Sale Price \& Charter Price in Gangnam-3gu and Gangbuk-3gu. Korea Real Estate Acad. Rev. 2017, 70, 17-27.

29. Myers, J.L.; Well, A.D.; Lorch, R.F., Jr. Research Design and Statistical Analysis, 3rd ed.; Routledge: Abingdon, UK, 2013; pp. 467-492.

30. Lee, S.H. Job Quality and Social and Economic Inequalities in the Region. Reg. Employ. Trends Brief 2019.

31. Cayla, J.-M.; Maizi, N.; Marchand, C. The role of income in energy consumption behavior: Evidence from French households' data. Energ. Pol. 2011, 39, 7874-7883. [CrossRef]

32. Druckman, A.; Jackson, T. Household energy consumption in the UK: A highly geographically and social-economically disaggregated model. Energ. Pol. 2008, 36, 3167-3182. [CrossRef]

33. Huang, W.-H. The determinants of household electricity consumption in Taiwan: Evidence from quantile regression. Energy 2015, 87, 120-133. [CrossRef]

34. McLoughlin, F.; Duffy, A.; Conlon, M. Characterising domestic electricity consumption patterns by dwelling and occupant socio-economic variables: An Irish case study. Energ. Build. 2012, 48, 240-248. [CrossRef]

35. Seoul Metropolitan Government. Seoul Open Data Plaza. Available online: https://data.seoul.go.kr/ (accessed on 1 August 2020).

36. Byun, M.R.; Min, B.G.; Park, M.J. An empirical analysis of the spatial distribution and flow patterns of Seoul's single-person households. Korea J. Popul. Stud. 2019, 42, 91-119. [CrossRef]

37. Yohanis, Y.G. Domestic energy use and households' energy behavior. Energ. Pol. 2012, 41, 654-665. [CrossRef]

38. Fell, H.; Li, S.; Paul, A. A new look at residential electricity demand using household expenditure data. Int. J. Ind. Organ. 2014, 33, 37-47. [CrossRef]

39. Sung, Y.-A. A comparison of consumption expenditure patterns and their determinants of elderly and nonelderly households. J. Korean Econ. Assoc. 1997, 35, 103-117.

40. Europe's Energy Portal. EU Energy Prices_July 2019. Available online: https://www.energy.eu/electricity_ natural-gas_prices_european_union/ (accessed on 17 August 2020).

41. Clean Energy Wire. What German Households Pay for Power. Available online: https://www.cleanenergywire. org/factsheets/what-german-households-pay-power (accessed on 17 August 2020).

42. Korean Federation for Environmental Movement. [Press Release] Citizens' Perception Survey on climate change. Available online: http://ecoseoul.or.kr/archives/23782 (accessed on 20 August 2020).

Publisher's Note: MDPI stays neutral with regard to jurisdictional claims in published maps and institutional affiliations.

(C) 2020 by the author. Licensee MDPI, Basel, Switzerland. This article is an open access article distributed under the terms and conditions of the Creative Commons Attribution (CC BY) license (http://creativecommons.org/licenses/by/4.0/). 